\title{
Exílios, políticas e espaços: entrevista com Adriana Amante
}

\author{
FÁBIO VARELA NASCIMENTO \\ Pontifícia Universidade Católica do Rio Grande do Sul - Porto Alegre - Rio Grande do Sul - Brasil
}

Adriana Amante é doutora em Letras pela Universidad de Buenos Aires (UBA). Além de ser professora de Literatura Argentina do século XIX na UBA e na New York University de Buenos Aires, é pesquisadora do Instituto de Literatura Hispano-Americana da UBA e diretora acadêmica da Escuela Superior de Creativos Publicitarios. Recebeu bolsas do Fondo Nacional de las Artes, do Instituto Camões e da UBA e foi pesquisadora visitante na New York University, na University of London y na Universidade Nova de Lisboa. Publica artigos e ensaios em diversas revistas especializadas, edita textos de autores clássicos argentinos e traduz obras de Machado de Assis e Fernando Pessoa. Integra o conselho editorial da revista las ranas - artes, ensayo e traducción. Entre suas publicações, estão: Absurdo Brasil - polémicas en la cultura brasileña, compilação organizada com Florencia Garramuño, de 2000, Poéticas y politicas del destierro - argentinos en Brasil en la época de Rosas, de 2010, realizada com o apoio do Fondo de Cultura Económica.

A entrevista com a professora Adriana Amante foi realizada no dia 6 de outubro de 2015, durante o XI Seminário Internacional de História da Literatura, no prédio da Faculdade de Letras da Pontifícia Universidade Católica do Rio Grande do Sul. O tema da conversa foi a sua obra Poéticas y políticas del destierro - argentinos en Brasil en la época de Rosas.

Fábio Varela Nascimento - Seu livro Poéticas y políticas del destierro tem como ponto fundamental o espaço, que vária de um território, como o Brasil, a Argentina, a um lugar menor, com o Instituto Histórico e Geográfico Brasileiro ao Salón. Acho que nossa conversa pode iniciar por esse caminho. Em primeiro lugar, através das suas leituras das cartas e das obras desses exilados, como a senhora percebe o choque dos argentinos com o clima, a geografia e as pessoas do Rio de Janeiro, do Brasil, desse outro Oriente?

ADRIANA AMANTE - Eu comecei a prestar atenção no problema do espaço, antes de nada, porque eu tinha vontade de fugir da ciência política e da teoria política como único caminho de pensar o exílio. Eu achava que já havia um monte de livros escritos sobre isso e que todo mundo ia por lá. Eu estava nos Estados Unidos, em Nova York, passando um ano, fazendo um curso de doutorado e pesquisando, e descobri a geografia cultural. Tinha sido lançado o livro de Edward Soja naquele momento, Thirdspace, que era sobre Los Angeles. Então, comprei o primeiro livro dele, Postmoderns Geographies, e li como uma espécie de introdução ao problema da geografia cultural. Fiquei encantada. Fui lendo David Harvey, Derek Gregory e consegui entender que um dos problemas mais importantes para pensar era aquele do espaço, do espaço nacional, e de como as naturezas diferentes podiam ter soluções parecidas e, muitas vezes, determinar, de modo distinto, o modo de representação. Fiquei encantada porque tem uma linha que é mais do assunto superficial - aquela que todo argentino que veio para o Brasil falava do calor, falava do sol. Mas apareceu uma coisa de percepção muito importante, porque, no caso do Mármol, que falava e cantava as montanhas do Brasil como se fossem os Alpes, que eles não tinham, havia relação com uma questão de proporção e, então, o modo de pensar, de ver, começou a ser um ponto muito importante. Ele falava, em uma nota de rodapé do seu poema, que muitas pessoas poderiam criticar o exagero do argentino, mas ele também falava que, quando você está acostumado a ter só uma linha, qualquer elevação é muita. Então, isso, eu podia ver. No caso de Sarmiento, tem uma intervenção política mais central, pois ele falava 
que, mesmo numa natureza exuberante, impossível de dominar, como a brasileira, se tinha um projeto político civilizado, progressista - como aquele do Pedro II. Era possível mensurar, limitar e dominar essa natureza para o projeto de civilização. Mas, aí, ele falava louvando o projeto de Pedro II, por ele colocar esse modelo como contrário àquele de Rosas, que não dominava, não orientava a natureza para o desenvolvimento civilizatório, se deixava dominar pela imperícia, pela negligência e por tudo que a natureza determinante da Argentina marcava como futuro.

FVN - Ainda nessa ideia de choque, também pela percepção das suas leituras, como foi o comportamento dos argentinos frente à monarquia "aberta" de Pedro II, um imperador ainda nos vinte anos, com a ideia de agregar os intelectuais no projeto nacional, mas que, ao mesmo tempo, dirigia um regime escravocrata e dependente dessa mão de obra? O comportamento do Sarmiento, por exemplo, se modifica um pouco se olharmos as suas primeiras impressões em relação às posteriores, feitas após as conversas com o imperador. AA - Sarmiento sempre mudava e isso causava um enfado tremendo ao Alberdi, que falava: "Você, há dois anos, pensava tal coisa e, agora, pensa o contrário". Ele [Sarmiento] falava: "Se mudarem as condições, eu vou mudar de posição". Ele tinha muito claro que a política era a arte da acomodação ao tempo e ao espaço. O ponto central da minha tese talvez seja esse que você assinalou: eles tinham inveja, inveja mesmo, da relação que o imperador tinha com os artistas porque eles pretenderam isso com o Rosas e não deu. Tentaram, não é que só ficaram por fora do regime. Eles tentaram ser os conselheiros de Rosas, não puderam, pois ele não aceitava e não ligava pra eles. Só ligou em um momento, com o Alberdi. Eles pediam para Rosas fazer uma constituição. Se ele tivesse feito, a história seria muito diferente e teria sido possível uma aliança. Eles vieram para o Brasil e foi surpreendente, mas não tinham a expertise para entender que o fato de Pedro II apoiar a arte era, também, uma estratégia política. Eles não ligaram para isso. Não sabiam, nem queriam saber porque era suficiente ter esse modelo como um modelo oposto àquele de Rosas. O Sarmiento tinha, além disso, uma questão muito pessoal, vaidosa, que era a de encontrar um poderoso que estava atento a tudo que ele escreveu. Para ele, isso [o encontro com D. Pedro II] foi determinante, não só perante o Rosas, que lia o Sarmiento e lia bem o Sarmiento. Mais do que com Rosas, era com Urquiza, porque, quando ele veio e teve essas entrevistas com o imperador, em 1852, tinha ocorrido a Batalha de Caseros, a batalha na qual o Rosas foi embora, e Sarmiento foi acompanhando Urquiza, que era muito mais malvado do que Rosas e tinha lido tudo que Sarmiento tinha escrito, mas fazia de conta que nem ligava para isso. Sarmiento ficava raivoso e falava: "Ele está propondo modelos de política que leu nos meus livros, mas não me nomeia". Acho que isso aí é um modelo muito diferente, mas todo mundo, todo argentino que veio para o Brasil falou que a escravidão era impossível, inumana e, mesmo, inconcebível em termos econômicos. Mas Sarmiento, no ano de 1844, antes de vir para o Brasil, quando estava pensando na América, achava que, mesmo não sendo tolerável a escravidão, era parte do que tinha de ser aceito para que a monarquia estivesse firme contra a Revolução Farroupilha, que era muito mais perigosa por estar orientada pela influência do caudilho argentino, que desorganizaria o país. Então, aí, ele disse: "Eu não aceito, mas é preciso suportar".

FVN - Acho que outra pergunta pode ter relação com essa. A senhora não acha que o José Mármol, por exemplo, na "Juventude progressista", exige dos brasileiros uma atitude argentina? Nós não estávamos na mesma etapa de independência da Argentina. Nosso processo foi mais suave, quase sem sangue. Quando Pedro I abdicou em favor de uma criança, também houve pouco sangue. Houve rebeliões, como a Revolução Farroupilha, mas poucas tiveram, realmente, caráter independentista, poucos quiseram mudar a forma de governo. A imprensa era situacionista. A classe pensante brasileira, os intelectuais estavam na mão do imperador. Aqui, não existia a ideia de escrever contra, mas a ideia de escrever a favor.

AA - Mármol exige aquilo que experimentou na Argentina porque ele era mais novo do que o resto. Quando ele estava na Argentina, com o Salón Literário e tal, ele tinha só 17 anos. Alguns estudiosos acham que ele participou, mas só como ouvinte. Mas, nesse sentido, foi um movimento muito importante de juvenilismo e eles ficaram muito valentes com isso. Ele foi muito depreciativo a respeito do Brasil e da juventude por que era a colocação típica argentina, mas, também, do argentino que tinha feito obra. Nem tanto ele, mas do jeito de a juventude ter a visão de mudar o futuro. Mas, em favor dele, poderíamos dizer que o que eles estavam assinalando, orientando para os brasileiros, era a necessidade de serem repúblicas numa América que já não tinha a vontade de continuar a ser monárquica. Então, eu apoio. Acho que eles, aí, iam por diante de outras ideias. Mas, em geral, ele teve uma atitude que tinha a ver, também, com a sua colocação. Ele veio para o Brasil como um opositor de Rosas, fugindo de Montevidéu e ficou aqui em caráter de, talvez, duplo agente, porque ele era o opositor de Rosas, mas, também se fala, e disso não há provas, mas é possível, de que ele tenha sido o filho do representante de Rosas 
perante o Pedro II, o diplomata Tomás Guido. Então, ele tinha uma colocação entre a juventude opositora, que estava fazendo um poema muito elogiado, mesmo pelo Sarmiento, e essa colocação diplomática, de informação. Mas, também, o meio intelectual, o meio romântico do primeiro romantismo brasileiro era um pouquinho só de, como era?, "menino manhoso longe da mãe". Alguém me falava isso do Gonçalves de Magalhães. Não era. Era aquilo que tinha de ser porque estava na hora, mas não era um produto natural de uma revolta política como tiveram Portugal, Argentina e França. Era débil. Então, essa percepção de que, mesmo sendo o Domingos Gonçalves de Magalhães o equivalente, como falou o Joaquim Norberto, do Esteban Echeverría e, mesmo com o Echeverría que nem sempre escrevia coisa muito nobre. Eu acho que o Domingos Gonçalves de Magalhães foi importante para abrir um caminho, mas não foi um grande criador. Foi preciso esperar até Alencar para vocês terem um Romantismo forte. Aí, há uma colocação entre aquele que pode ver de longe e esse jeitinho argentino de falar o que é preciso fazer. Muito mais lúcido, nesse sentido, foi Sarmiento. Há pouco descobri que o Alberdi, que sempre foi muito mesurado politicamente, não tinha essa paixão do Sarmiento, tem uma obra de teatro, que não concluiu, dedicada aos farrapos. Ele foi talvez o único, com mais um uruguaio chamado Juan Carlos Gomes, que tinha motivos pessoais e familiares para estar contra o regime do Pedro II, que falou disso, no ano de 1839. O Alberdi disse que via, na Revolução Farroupilha, um fermento revolucionário jovem parecido com a causa argentina e ele sentia que, mais do que colocar-se por cima, como o Mármol, quando faz isso, de irmãos, que estava num contexto muito diferente, experimentando um tipo de revolta fundamental para o futuro de cada uma das nações.

FVN - Em relação à questão anterior, eu queria que a senhora falasse um pouco sobre os projetos nacionais da Argentina e do Brasil. Os intelectuais brasileiros queriam construir a imagem do "Brasil natureza", os argentinos, da "Argentina civilização". A chegada dos argentinos reforça a ideia do Brasil só natureza, mas, e os brasileiros, eles chegam a falar, de alguma forma, da imagem da Argentina civilização?

AA - Talvez, as propostas do Sarmiento mesmo, já que ele é o teórico e quem mais fala da necessidade de que a civilização fique por cima da barbárie, na pessoa mesmo de Pedro II, é fundamental para pensar que lidaram com essa ideia. O Joaquim Norberto nem falava nisso nem ligava para isso. Talvez, sim, quando eles aceitam ir contra o Rosas, para impor, não o modelo de Urquiza, acho que Urquiza era só um meio de acabar com Rosas, mas, talvez, sim, o tipo de projeto de nação, que ia aumentando e que era aquele que o Sarmiento professava mesmo quando ele ainda não era o que chegaria a ser. Talvez, sim, acabar com o modelo da barbárie. Esse modelo ameaçava a unidade do império. Lembro algumas palavrinhas, mas não de uma teoria forte de civilização. Acho que mais como um conceito geral que era de bom tom ser civilizado, mas não como sistema de interpretação política. Mas, o Sarmiento, sim, aplicou o sistema da dicotomia civilização x barbárie ao Brasil.

FVN - A senhora faz uma oposição entre dois espaços muito interessantes: Petrópolis, a cidade erguida por Pedro II, e a casa que Rosas construiu em Palermo. Gostaria que a senhora me falasse sobre a representatividade política e intelectual desses dois lugares, das relações que poderiam se estabelecer neles.

AA - Acho que Sarmiento coloca o modelo de Pedro II em contraposição ao de Rosas, porque é muito esquisito o fato de Rosas ter um modelo arquitetônico republicano, sem fausto, sem luxo, sem excesso econômico e Sarmiento, que era muito republicano, não aceitar. Não posso deixar de ver que isso não era um problema. Isso era uma coisa boa do Rosas, mas Sarmiento estava tão enfadado com Rosas que nem aceitou e preferiu, nesse sentido, o modelo econômico de Petrópolis. Mas há duas coisas, por um lado, você tem a casa mesmo de Rosas, que é isso, não consigo compreender o porquê de Sarmiento não aceitar. Acho que não aceitou porque estava pensando como opositor, absolutamente obsecado pela oposição. O modelo arquitetônico que não só Rosas, mas seus colaboradores pediam, era aquele republicano, muito singelo, muito simples, mas, no caso de Petrópolis, não é só a casa mesmo do imperador que, quando Sarmiento chegou, veio pela primeira vez, em 1846, ele achava que era mamarracho, paródia. Mas, sim, e, nisso, Sarmiento é muito consequente com a sua ideia, o modelo de colônia produtiva economicamente que foi Petrópolis. Isso aí, ele celebrou e, nesse sentido, tem coerência com o que falava no Facundo, do tipo de colônia alemã frente à Vila Nacional, que era pobre.

FVN - Também gostaria que a senhora falasse de espaços menores: o IHGB e o Salón. O IHGB tinha a bênção do imperador, que frequentava mais as sessões do Instituto do que da Câmara, tinha, também, um modo de funcionamento. Mas, e o Salón, como funcionava? Não poderia ser apenas um lugar de leituras, era um lugar, antes de tudo, de relações.

AA - Funcionava, em primeira instância, como gabinete de leitura. Era um local de circulação de conversas, de livros, de conhecimento, que tinha começado em casas particulares. Não era usual ter livrarias ou mesmo salões boticários que eram salões de leitura. Aqui se produz uma confluência do interesse intelectual de ler o que vem da 
França com o interesse por pensar políticas e jeitos de combinar a prática literária com a política. No começo, Rosas deixou fazer, não ligava pra isso e nem ia [às reuniões]. Tudo ao contrário de Pedro II. O Salón não era um local institucional, era uma empresa privada, desse homem chamado de Marcos Sastre, que tinha uma livraria. Rosas, depois, caiu na conta de que era um pouquinho perigoso esses caras jovens falando de certas coisas. Mas, no Salón, conviviam, no começo, rosistas e antirrosistas. $\mathrm{O}$ que a Rosas faltou foi o projeto institucional de fazer coisas com a arte e a ciência. Todo mundo critica que ele não incentivou e até mesmo fechou universidade, agrupações médicas. Ele não fez nada institucional para fomentar a ciência. Mas ele também fomentou trabalhos como aquele de Francisco Javier Muñiz, um médico e paleontólogo muito importante. Talvez, a diferença fundamental é que o Pedro II achou que a institucionalização, como avanço, como desenvolvimento e como projeto para apoiar, era fundamental para o seu projeto político. Ele sentiu, ele era mais culto, em geral, tinha a ver com a sua colocação e a sua herança, mas ele também foi experto em ver como um certo tipo de instituição era útil a um projeto que se prolongou muito no tempo. Rosas não pode construir isso. O Uruguai teve um instituto histórico similar, na mesma época, que, depois, acabou se dissolvendo. A instituição, na Argentina, de forma muito geral, o momento institucional foi aquele de Rivadavia, do ano de 1826. Depois, todo mundo fala que o Rosas deixou cair aquilo que tinha sido institucionalizado e desenvolvido muito a arte e a ciência nessa época. Então, era como um contraste.

Recebido: 10 de novembro de 2015 Aprovado: 21 de dezembro de 2015 Contato: fv.nasci@gmail.com 